\title{
Lower Incidence of Hypo-Magnesemia in Surgical Intensive Care Unit Patients in 2011 Versus 2001
}

\author{
John T. Denny a, c, Enrique Pantin ${ }^{\mathrm{a}}$, Antonio Chiricolo ${ }^{\mathrm{a}}$, James Tse ${ }^{\mathrm{a}}$, Thomas Jan ${ }^{\mathrm{a}}$, Mohammad Chaudhry ${ }^{\mathrm{a}}$, \\ Sylviana Barsoum ${ }^{\mathrm{a}}$, Angela M. Denny ${ }^{\mathrm{b}}$, Denes Papp ${ }^{\mathrm{a}}$, Sharon L. Morgan ${ }^{\mathrm{a}}$
}

\begin{abstract}
Background: Hypo-magnesemia is described to occur in as many as $65 \%$ of intensive care unit (ICU) patients. Magnesium $(\mathrm{Mg})$ is a cofactor in over 300 enzymatic reactions involving energy metabolism, protein, and nucleic acid synthesis. The membrane pump that creates the electrical gradient across the cell membrane is dependent on $\mathrm{Mg}$, and it is important in the activity of electrically excitable tissues. Since $\mathrm{Mg}$ regulates the movement of calcium in smooth muscle cells, it is also important in peripheral vascular tone and blood pressure. Studies have linked hypo-magnesemia to multiple chronic diseases and to a higher mortality rate.
\end{abstract}

Methods: To explore trends within our own tertiary care surgical ICU, we sampled our patients' laboratory records in 2001 and in 2011. Hypo-magnesemia in our ICU is defined as an Mg less than $2.0 \mathrm{mg} / \mathrm{dL}$.

Results: This retrospective review of all SICU patients from October to December revealed that there was a significant increase $(\mathrm{P}<0.01)$ in the patients with their serum $\mathrm{Mg}$ level measured between 2001 $(89 \%)$ and 2011 (95\%). There was a significant decrease $(\mathrm{P}<0.001)$ in patients with hypomagnesemia $(<2 \mathrm{mg} / \mathrm{dL})$ between $2001(47.5 \%)$ and $2011(33.0 \%)$. On the other hand, there was a significant increase $(\mathrm{P}<0.001)$ in patients with normal serum $\mathrm{Mg}$ level $(>2 \mathrm{mg} / \mathrm{dL})$ between $2001(52.5 \%)$ and $2011(67.0 \%)$.

Conclusions: There was not only more monitoring of $\mathrm{Mg}$ in 2011, but a lower incidence of hypo-Mg compared to 2001. Possible explanations include changing patterns of antibiotic and diuretic use, less amphotericin use, more frequent laboratory surveillance, and better trained ICU practitioners.

Manuscript accepted for publication January 26, 2015

aRutgers Robert Wood Johnson Medical School, 3100 CAB, 125 Paterson Street, New Brunswick, NJ 08901, USA

bRutgers Graduate School of Nursing, 65 Bergen Street, Newark, NJ 07107, USA

${ }^{\mathrm{c} C o r r e s p o n d i n g ~ A u t h o r: ~ J o h n ~ T . ~ D e n n y, ~ R u t g e r s ~ R o b e r t ~ W o o d ~ J o h n s o n ~ M e d i-~}$ cal School, 3100 CAB, 125 Paterson Street, New Brunswick, NJ 08901, USA. Email: dennyjt@rwjms.rutgers.edu

doi: http://dx.doi.org/10.14740/jocmr2101w
Keywords: Magnesium; Hypo-magnesemia; Divalents in ICU; Electrolyte abnormalities

\section{Introduction}

Hypo-magnesemia is a common laboratory abnormality encountered in hospitalized patients. It is found in as many as $20 \%$ of medical floor patients [1]. It has been described to occur in as many as $65 \%$ of patients in intensive care units (ICUs) [2]. Magnesium (Mg)'s importance as an essential nutrient has been realized since Kruse in 1932 described the effects of acute $\mathrm{Mg}$ deficiency in rats [3]. It is the second most plentiful intracellular cation, and the fourth most occurring cation in the body [4]. The physiologically active form of the element is ionized. Protein-bound and chelated $\mathrm{Mg}$ buffer the ionized pool. Approximately $50 \%$ of the total $\mathrm{Mg}$ in the body is present intracellularly in soft tissue, while the other half is present in bone. Only $0.3 \%$ of total body $\mathrm{Mg}$ is present in the serum [2], while less than $1 \%$ of the total body $\mathrm{Mg}$ is present in blood [4]. Estimates of $\mathrm{Mg}$ deficiency range from $20 \%$ to $65 \%[2,5,6]$. Rubeiz et al found that reductions in total serum $\mathrm{Mg}$ found at hospital admission are associated with increased mortality [7]. Sakaguchi et al found that hypomagnesemia was significantly associated with an increased risk of mortality in hemodialysis patients [8]. Guasch-Ferre et al reported an inverse relationship between dietary $\mathrm{Mg}$ ingestion and mortality in patients with elevated cardiovascular risk [9].

\section{Methods}

Our 17-bed trauma/surgical ICU (SICU) is part of a 600-bed tertiary care hospital that is a designated level one trauma center. The SICU admits patients with surgical issues, and trauma patients. Patient age ranges from 21 to 105 years old. Patients younger than 21 years old are admitted to the pediatric ICU at our institution. Critically ill patients get laboratory studies drawn at $1 \mathrm{am}$ each day. If conditions warrant, they often have repeat labs done throughout the day. We reviewed patient records for 2001 and 2011. All lab values in the SICU during this time were recorded. The last 3 months of each year were 
Table 1. Sex and Average Age of SICU Patients During October to December in 2001 and 2011

\begin{tabular}{llll}
\hline October - December & Number of SICU patients & Sex & Average age (years) \\
\hline 2001 & 67 & $48.9 \%$ male & 61.4 \\
2011 & 50 & $52.2 \%$ male & 66.2 \\
\hline
\end{tabular}

selected to compare similar times. $\mathrm{Mg}$ levels less than 2.0 were below our normal ICU range and were noted.

\section{Results}

This retrospective review shows that there were 67 SICU patients in 2001 and 50 SICU patients in 2011 during October to December (Table 1). There was similar ratio of male vs. female patients and average age of SICU patients during these periods. The diagnosis and surgical procedures included: s/p open abdominal aortic aneurysm (AAA) repair, s/p perforated duodenal ulcer, status epilepticus, s/p carotid endarterectomy, liver laceration, pancreatic abcess, renal laceration, liver cancer, colon perforation, rib fractures/hemothorax, DVT, subarachnoid hemorrhage/hydrocephalus, facial fractures, pituitary tumor, subarachnoid hemorrhage/vasospasm, s/p radical cystectomy, $\mathrm{s} / \mathrm{p}$ small bowel resection, $\mathrm{s} / \mathrm{p}$ perforated diverticulitis, brain tumor, closed head injury, $\mathrm{s} / \mathrm{p}$ excision of pelvic mass, subdural hematoma, pelvic fracture, femur fracture, cholangitis, intracranial hemorrhage, bowel obstruction, foot gangrene/PVD, splenectomy, splenic laceration, enterocutaneous fistula, subarachnoid hemorrhage, spinal cord injury, cerebral aneurysm, spine fracture, skull fracture, pancreatitis, hemorrhagic cystitis, brain metastasis, colon cancer, renal cell cancer, pancreatic cancer, spinal stenosis, spinal tumor, bowel ischemia, gunshot wound to chest, pancreas renal transplant, thoracic aneurysm, ARDS, s/p endovascular AAA, esophageal perforation, s/p esophageal cancer, rib fractures, rectal cancer, uterine bleeding, infected vascular graft, pulmonary embolus, pseudoaneurysm, and $\mathrm{s} / \mathrm{p}$ brain stimulator.

The total number of electrolyte determinations was 314 in 2001 and 296 in 2011. The average number of electrolyte determination was 4.69 per patient in 2001 and 5.92 per patient during October to December. There was a significant increase $(\mathrm{P}<0.01)$ in electrolyte determinations with serum $\mathrm{Mg}$ level measured between 2001 (89\%) and 2011 (95\%) (Table $2)$. There was a significant decrease $(\mathrm{P}<0.001)$ in electrolyte determinations with hypomagnesemia $(<2 \mathrm{mg} / \mathrm{dL})$ between
2001 (47.5\%) and 2011 (33.0\%) (Table 2). On the other hand, there was a significant increase $(\mathrm{P}<0.001)$ in electrolyte determinations with normal serum $\mathrm{Mg}$ level $(>2 \mathrm{mg} / \mathrm{dL})$ between $2001(52.5 \%)$ and 2011 (67.0\%) (Table 2).

\section{Discussion}

This retrospective review of all SICU patients from October to December revealed that there was a significant increase $(\mathrm{P}$ $<0.01$ ) in the patients with their serum Mg level measured between 2001 (89\%) and 2011 (95\%) (Table 1). There was a significant decrease $(\mathrm{P}<0.001)$ in patients with hypomagnesemia $(<2 \mathrm{mg} / \mathrm{dL})$ between $2001(47.5 \%)$ and $2011(33.0 \%)$ (Table 1). On the other hand, there was a significant increase $(\mathrm{P}$ $<0.001)$ in patients with normal serum $\mathrm{Mg}$ level $(>2 \mathrm{mg} / \mathrm{dL})$ between 2001 (52.5\%) and 2011 (67.0\%) (Table 1).

There are several non-mutually exclusive explanations possible for these results. One is the improved understanding of the importance of $\mathrm{Mg}$ in hospitalized patients. In the decade since the first sampling, it is possible that $\mathrm{Mg}$ is being monitored more regularly in ICU patients. The slightly higher number of samples per patient in 2011 suggests this: The average number of electrolyte determination was 4.69 per patient in 2001 and 5.92 per patient during October to December. One reason for this might be the increased prevalence of ICU fellowship training among practitioners in the ICU.

It is important for ICU practitioners to be aware of hypomagnesemia since $\mathrm{Mg}$ is a cofactor in over 300 enzymatic reactions involving energy metabolism, protein, and nucleic acid synthesis [4]. The membrane pump that creates the electrical gradient across the cell membrane is dependent on $\mathrm{Mg}$. Thus $\mathrm{Mg}$ is important in the activity of electrically excitable tissues [10]. Since $\mathrm{Mg}$ regulates the movement of calcium in smooth muscle cells, it is important in peripheral vascular tone regulation and in cardiac contractile strength. Because $\mathrm{Mg}$ is a cofactor for ATPase reactions, deficiency could lead to defects in cellular energy utilization.

Other electrolyte disturbances often co-exist with hypo-

Table 2. Comparing Serum Magnesium Levels in SICU Patients During October to December During 2001 and 2011

\begin{tabular}{|c|c|c|c|c|c|}
\hline & $\begin{array}{l}\text { Number of SICU } \\
\text { patients during } \\
\text { October - December }\end{array}$ & $\begin{array}{l}\text { Total electrolyte } \\
\text { determinations } \\
\text { during October } \\
\text { - December }\end{array}$ & $\begin{array}{l}\text { Electrolyte } \\
\text { determinations } \\
\text { with serum Mg } \\
\text { level measured }\end{array}$ & $\begin{array}{l}\text { Electrolyte } \\
\text { determinations with } \\
\text { hypo-Mg level } \\
(<2 \mathrm{mg} / \mathrm{dL})\end{array}$ & $\begin{array}{l}\text { Electrolyte } \\
\text { determination with } \\
\text { normal } \mathrm{Mg} \text { level } \\
\text { (>2 mg/dL) }\end{array}$ \\
\hline $2001(\mathrm{~N})$ & 67 & 314 & $280(89 \%)$ & $133(47.5 \%)$ & $147(52.5 \%)$ \\
\hline $2011(\mathrm{~N})$ & 50 & 296 & $282(95 \%)$ & $93(33.0 \%)$ & $189(67.0 \%)$ \\
\hline 2001 vs. 2011 & & & $\# \mathrm{P}<0.01$ & $* \mathrm{P}<0.001$ & $* \mathrm{P}<0.001$ \\
\hline
\end{tabular}

\#*Significantly different between 2001 and 2011, Chi-square test. 
magnesemia. The hypokalemia that accompanies Mg deficiency is often resistant to simply replacing the potassium, and repleting the hypo-magnesemia can be necessary before potassium repletion can be accomplished.

However, because an overall body $\mathrm{Mg}$ deficiency may not be accompanied by hypo-magnesemia, the true incidence of $\mathrm{Mg}$ depletion is higher than what is detected by the Mg concentration in blood. Since serum $\mathrm{Mg}$ levels are not a perfect reflection of total body $\mathrm{Mg}$, it is important to recognize other conditions that can lead to an underlying hypo-magnesemia.

Causes of hypo-magnesemia in the ICU population are diverse. Diuretic therapy is the leading cause of $\mathrm{Mg}$ deficiency. Diuretic induced inhibition of sodium resorption will also interfere with $\mathrm{Mg}$ resorption. Urinary $\mathrm{Mg}$ excretion is most with the loop diuretics (furosemide and ethacrynic acid). Antibiotics which also promote $\mathrm{Mg}$ depletion are the aminoglycosides and amphotericin [11]. Antibiotic associated diarrhea can also be accompanied by significant $\mathrm{Mg}$ stool losses. Other drugs associated with $\mathrm{Mg}$ depletion include digoxin and epinephrine, which shift $\mathrm{Mg}$ into cells [12]. In contrast, the chemotherapeutic agents cyclosporine and cisplatin promote renal $\mathrm{Mg}$ excretion [12].

Proton pump inhibitors are known to lower serum Mg levels in a variety of patients [13-15]. Their use has increased over the years in question. Since $\mathrm{Mg}$ concentration is high in lower gastrointestinal secretions, a secretory diarrhea can lead to $\mathrm{Mg}$ depletion [16]. A change in any incidence of prescribing any of the above medications could affect the incidence of hypo-magnesemia observed.

Acute myocardial infarction may be accompanied by hypo-magnesemia in up to $80 \%$ of patients in the first $48 \mathrm{~h} \mathrm{[17].}$ Chakraborty et al also showed significantly lower Mg levels in patients with acute myocardial infarctions [18]. An et al studied patients younger than 50 years old who had drug eluting stents placed. In patients with subsequent myocardial infarction, after adjusting for age, positive family history, smoking status, hypertension, hypercholesterolemia, and diabetes at baseline, the risk was 8.11-fold higher for patients with quartile 1 of $\mathrm{Mg}$ levels than quartile $4 \mathrm{Mg}$ level. In addition, when tested as a continuous variable, serum $\mathrm{Mg}$ was a significant predictor for major adverse cardiac events of acute myocardial infarction after adjustment for other confounders [19]. Dibaba et al performed a meta-analysis and systematic review indicating that dietary $\mathrm{Mg}$ intake is significantly and inversely associated with serum C-reactive protein levels. They suggest that any potential beneficial effect of $\mathrm{Mg}$ intake on chronic diseases may be, at least in part, explained by inhibiting inflammation [20].

Insulin-dependent diabetic patients can exhibit hypomagnesemia as a result of glycosuria producing urinary $\mathrm{Mg}$ losses [21]. Yang et al found that postpartum serum $\mathrm{Mg}$ level was also a possible predictor for development of type II DM and that serum $\mathrm{Mg}$ level in the postpartum period may be a possible predictor for type II DM development in women with a history of gestational DM [22].

Alcohol use is a very common occurrence in the trauma population. Alcohol is associated with perturbations in $\mathrm{Mg} \mathrm{lev-}$ els. Hypo-magnesemia is seen in $30 \%$ of hospital admissions for alcohol abuse, and in $85 \%$ of delirium tremens admissions $[16,23]$. Hypo-magnesemia may be a common laboratory clue towards alcohol abuse in a hospitalized patient who is noncommunicative (for example, an unconscious trauma patient, in whom a medical history is unobtainable).

\section{Study limitations}

The incidence of alcohol abuse was not measured in our study, so we cannot comment on the influence of alcohol on our patients' hypo-magnesemia. Mg concentration is high in lower gastrointestinal secretions, and a secretory diarrhea can lead to $\mathrm{Mg}$ depletion [16]. We did not measure the incidence of Clostridium difficile $(C$. diff) colitis in the two time periods; however, some institutions report an increased incidence of $C$. diff. In addition, the emergence of the NAP1/BI/O27 strain of C. diff. in the early 2000s has been associated with more severe forms of $C$. diff. [24]. Likewise, we were not able to quantitate the incidence of diuretic use which could affect $\mathrm{Mg}$ levels. Changing patterns of antibiotic and anti-fungal use could also influence the incidence of hypomagnesemia. Certainly much less amphotericin (which can produce hypo-magnesemia) is being used now than in 2001. Conversely, more proton pump inhibitors, which are known to often decrease $\mathrm{Mg}$ levels, were being used in 2011 than in 2001. This study was designed to investigate trends in $\mathrm{Mg}$ levels over 10 years in the SICU population. As such, it reflects all $\mathrm{Mg}$ levels measured in that 3 month period in the 2 years. We cannot therefore comment on trends in initial $\mathrm{Mg}$ levels upon initial admission to the SICU. Also we cannot address the effectiveness of $\mathrm{Mg}$ repletion on the results, since all lab values were examined. Likewise, our results reflect our patient population and cannot be generalized to other ICU populations.

\section{Conclusions}

In our tertiary hospital SICU sample, this retrospective review showed there was a significantly lower incidence $(\mathrm{P}<0.001)$ of patients with hypomagnesemia $(<2 \mathrm{mg} / \mathrm{dL})$ between 2001 (47.5\%) and 2011 (33.0\%). This is encouraging that $\mathrm{Mg}$ is more often within normal range a decade later in our SICU population. Possible contributors to this lower incidence include better practitioner training, more frequent laboratory monitoring, and changing patterns of diuretic and amphotericin use.

This retrospective review of all SICU patients from October to December revealed that there was a significant increase $(\mathrm{P}<0.01)$ in patients who had their serum $\mathrm{Mg}$ level measured between 2001 (89\%) and 2011 (95\%). On the other hand, there was a significant increase $(\mathrm{P}<0.001)$ in patients with normal serum Mg level (>2 mg/dL) between 2001 (52.5\%) and 2011 $(67.0 \%)$. These two findings show that $\mathrm{Mg}$ is being measured more often, and being more often maintained in the normal range in 2011 when compared to 2001. Further investigation is needed to better understand these factors.

\section{References}

1. Noronha JL, Matuschak GM. Magnesium in critical ill- 
ness: metabolism, assessment, and treatment. Intensive Care Med. 2002;28(6):667-679.

2. Tong GM, Rude RK. Magnesium deficiency in critical illness. J Intensive Care Med. 2005;20(1):3-17.

3. Kruse HD OE, McCollum EV. Symptomatology resulting from $\mathrm{Mg}$ deprivation. The Journal of biological chemistry. 1932;96:519-539.

4. Elin RJ. Magnesium: the fifth but forgotten electrolyte. Am J Clin Pathol. 1994;102(5):616-622.

5. Ryzen E, Wagers PW, Singer FR, Rude RK. Magnesium deficiency in a medical ICU population. Crit Care Med. 1985;13(1):19-21.

6. Chernow B, Bamberger S, Stoiko M, Vadnais M, Mills S, Hoellerich V, Warshaw AL. Hypomagnesemia in patients in postoperative intensive care. Chest. 1989;95(2):391397.

7. Rubeiz GJ, Thill-Baharozian M, Hardie D, Carlson RW. Association of hypomagnesemia and mortality in acutely ill medical patients. Crit Care Med. 1993;21(2):203-209.

8. Sakaguchi Y, Fujii N, Shoji T, Hayashi T, Rakugi H, Isaka $\mathrm{Y}$. Hypomagnesemia is a significant predictor of cardiovascular and non-cardiovascular mortality in patients undergoing hemodialysis. Kidney Int. 2014;85(1):174-181.

9. Guasch-Ferre M, Bullo M, Estruch R, Corella D, Martinez-Gonzalez MA, Ros E, Covas M, et al. Dietary magnesium intake is inversely associated with mortality in adults at high cardiovascular disease risk. J Nutr. 2014;144(1):55-60.

10. White RE, Hartzell HC. Magnesium ions in cardiac function. Regulator of ion channels and second messengers. Biochem Pharmacol. 1989;38(6):859-867.

11. Atsmon J, Dolev E. Drug-induced hypomagnesaemia: scope and management. Drug Saf. 2005;28(9):763-788.

12. Whang R, Oei TO, Watanabe A. Frequency of hypomagnesemia in hospitalized patients receiving digitalis. Arch Intern Med. 1985;145(4):655-656.

13. Broeren MA, Geerdink EA, Vader HL, van den Wall Bake AW. Hypomagnesemia induced by several protonpump inhibitors. Ann Intern Med. 2009;151(10):755-756.

14. Danziger J, William JH, Scott DJ, Lee J, Lehman LW, Mark RG, Howell MD, et al. Proton-pump inhibitor use is associated with low serum magnesium concentrations. Kidney Int. 2013;83(4):692-699.

15. Lindner G, Funk GC, Leichtle AB, Fiedler GM, Schwarz C, Eleftheriadis T, Pasch A, et al. Impact of proton pump inhibitor use on magnesium homoeostasis: a cross-sectional study in a tertiary emergency department. Int J Clin Pract. 2014;68(11):1352-1357.

16. Martin KJ, Gonzalez EA, Slatopolsky E. Clinical consequences and management of hypomagnesemia. J Am Soc Nephrol. 2009;20(11):2291-2295.

17. Abraham AS, Rosenmann D, Kramer M, Balkin J, Zion MM, Farbstien H, Eylath U. Magnesium in the prevention of lethal arrhythmias in acute myocardial infarction. Arch Intern Med. 1987;147(4):753-755.

18. Chakraborty PK, Hoque MR, Paul UK, Husain F. Serum magnesium status among acute myocardial infarction patients in Bangladesh. Mymensingh Med J. 2014;23(1):4145.

19. An G, Du Z, Meng X, Guo T, Shang R, Li J, An F, et al. Association between low serum magnesium level and major adverse cardiac events in patients treated with drug-eluting stents for acute myocardial infarction. PLoS One. 2014;9(6):e98971.

20. Dibaba DT, Xun P, He K. Dietary magnesium intake is inversely associated with serum C-reactive protein levels: meta-analysis and systematic review. Eur J Clin Nutr. 2014;68(4):510-516.

21. Sjogren A, Floren $\mathrm{CH}$, Nilsson A. Magnesium deficiency in IDDM related to level of glycosylated hemoglobin. Diabetes. 1986;35(4):459-463.

22. Yang SJ, Hwang SY, Baik SH, Lee KW, Nam MS, Park YS, Woo JT, et al. Serum magnesium level is associated with type 2 diabetes in women with a history of gestational diabetes mellitus: the Korea National Diabetes Program study. J Korean Med Sci. 2014;29(1):84-89.

23. Shane SR, Flink EB. Magnesium deficiency in alcohol addiction and withdrawal. Magnes Trace Elem. 1991;10(24):263-268.

24. To KB, Napolitano LM. Clostridium difficile infection: update on diagnosis, epidemiology, and treatment strategies. Surg Infect (Larchmt). 2014;15(5):490-502. 